\title{
A Fuzzy MCDM Approach for Structured Comparison of the Health Literacy Level of Hospitals
}

\author{
Abed Saif Ahmed Alghawli ${ }^{1 *}$ \\ Department of Computer Science, College of Sciences and Humanities \\ Prince Sattam Bin Abdulaziz University, Aflaj, Kingdom of Saudi Arabia
}

\author{
Adel A. Nasser ${ }^{2}$ \\ Department of Computer Science and Information Systems \\ Faculty of Science, Sa'adah University \\ Sa'adah, Yemen
}

\author{
Mijahed N. Aljober ${ }^{3}$ \\ Department of Computer Science \\ Faculty of Science, Hajjah University \\ Hajjah, Yemen
}

\begin{abstract}
The primary objective of this study is to develop a hybrid multi-criteria decision-making (MCDM) model to evaluate and compare the organizational health literacy responsiveness (OHLR) level of hospitals. To achieve this goal, the health literacy performance indicators are selected, some potential uses of single and hybrid MCDM and qualitative approaches for structured comparison purposes are illustrated, one more common hybrid approach based on the Fuzzy Analytic Hierarchy Process and fuzzy Delphi method was chosen, developed, and applied. To compare the proposed model with its classical non fuzzy version (Qualitative - AHP), a case study example on the effect of their implementation on a structured comparison decisions is conceded, and the Bland Altman agreement method is applied to compare the results obtained by them. The results present the suitability of the application of both hybrid approaches for solving the problem. It also shows that the application of them leads to a distinctive outcomes. Robust Fuzzy based outcomes, and small agreement interval $(<0.0113)$ and little average change level in the rates of the hospitals $(<2.08 \%)$ are observed between results acquired by the Fuzzy based approach and those which were defined by the other model. Based on these results, a fuzzy based model was recommended for structured comparison of the OHLR level of hospitals under uncertainty conditions. It supports sustainable planning practices, and helps with improvement and effectively distributes the necessary resources.
\end{abstract}

Keywords-Health literacy; the organizational health literacy standard; fuzzy analytic hierarchy process; fuzzy Delphi method; structured comparison

\section{INTRODUCTION}

Providing a healthy life for citizens, enhancing well-being for them, providing timely and reliable delivery of quality healthcare, granting access to quality essential healthcare services, reducing risk and cost of services, and improving health outcomes are considered some of the leading sustainable development targets of countries [1,2,3]. Corporate social responsibility is regarded as one way to achieve such targets [4]. To improve the sustainability status of organizations and to integrate the sustainability issues into the business of it, companies should plan their sustainable development, and corporate social responsibility practices based on the sustainability need of communities $[5,6]$.

\footnotetext{
*Corresponding Author
}

Measuring, prioritizing, and ranking healthcare practices are considered one way of achieving these goals [7-9]. However, the existence of unreasonable portions of citizens and patients with restricted health literacy in many developing societies and the adverse effects resulting from the increase and spread of this phenomenon negatively affects the use of healthcare, its costs, and output [10]. Additionally, it has adverse effects on health status and health service utilization [11]. This phenomenon is associated with increased transitional care needs [12], risk of death, and hospitalization [13]. So, the implication of low health literacy leads to an increase in the economic, social, and health burdens of individuals, societies, and countries, which negatively affects the implementation of a country's sustainable development plans in general and the health plans in particular. Studying and understanding the health literacy from a systemic perspective is based on an understanding of the inputs, processes, relationships, and outputs of many relevant components considered one of the recent research and application directions for developing solutions that limit the effects of this phenomenon $[14,15]$. The influential relationship between the individual's competencies, system's demands, and its complexities, where health literacy decisions and actions are taken, and the primary health literacy of an individual (health literacy abilities) in this system, is one of the fundamental justifications for this research and its applied directions $[10,16]$. The health literacy concept is used as a tool to [10]: simplify and understand the health systems, which are often complicated,, improve the service provided; structure services in ways that maximize simplicity of systems and reduce challenges that limit access for services, ensure meeting the necessary health literacy requirements and preferences of all individuals that the healthcare organization serves; and improve patient outcomes and healthcare quality.

Assessments of the real status of the organizational health literacy of health facilities is an essential requirement for improving the organizational health literacy outcomes in a way that ensures community service and achieves its sustainable development goals as well as choosing, controlling, and adapting measures to improve it. Ranking and prioritization of the health literacy factors and a comparison of the actual level of health literacy practices in healthcare sector 
facilities is considered one of the most important steps for health services planning and for health-oriented sustainable development and corporate social responsibility planning processes.

A structured comparison of the organizational health literacy responsiveness (OHLR) level of a healthcare organization helps to determine the preferred health literacy development areas, the companies suggested for healthcare sustainable development planning, and the planning of the social responsibility directions of companies. Additionally, it helps decision makers fairly, equally, and effectively allocate their resources.

Conducting a structured comparison of the level of implementation, allows stakeholders to allocate, distribute and manage the related support resources in a way that contributes achieving the fair and sustainable distribution of resources, and supports meeting the ethical, economic, environmental and legal social responsibilities $[1,3,4,5,6,10]$. For example, the government wants to determine and rank the healthcare institutions that are most in need to support, determine how should government resources be fairly distributed among them according to their real application gaps in the application of health literacy practices, classify the application factors into different groups in terms of their sustainable importance, taking into account local economic conditions, and distribute resources between hospitals at different improvement stages so that the most important aspects are supported first; such questions become more important when the countries concerned are poor, and cannot provide sufficient support to fully address the health literacy situation simultaneously.

On the other hand, international organizations and local institutions offer different support programs in this regard, and most of them only focus on one sub-field or set of specific areas of application, in a way that serves the orientations and objectives of the institution. Such organizations are mostly seeking to find out how theirs support resources can be fairly divided among institutions according to the actual needs of those institutions, and taking into account their economic, and legal obligations .

There are four main practical aspects to help decision makers in solving these challenges; the first aspect lies in assessing the actual reality of the application, and identifying the application gap for each of the concerned institutions, the second lies in determining the relative importance of the health literacy sub-domains and their indicators on a sustainable basis, the third aspect consists in conducting merger operations between the outputs of the two previous processes to obtain weighted scored levels of application, while, the fourth is devoted to structurally compare the evaluation results between organizations.

In practice, the organizational health literacy responsiveness can be measured directly or indirectly. Regrettably, there is no unanimously accepted standard. To approximate an organizational health literacy responsiveness level in organizations, lists of metrics or indicators are used, and most of them are measured qualitatively with some quantitative measures available. The qualitative method is one of the common methods that were being used increasingly for evaluation purposes; and researchers rely on it in their studies in many fields [17-19], and the field of study is no exception to that $[10,20,21]$. But, the qualitative approach is not always reliable, and the quantified version of metrics is still not as accurate as what humans perform in its development, and this can lead to possible impreciseness, errors in measurement process, and misinterpretations [22]. Furthermore, the specifics of the healthcare organizations, their business needs, priorities, and strategies all vary, and this means that the weights of the organizational health literacy responsiveness factors differed from one to another, and a structured comparison of the organizational health literacy responsiveness level metric between healthcare organizations, or between branches, is not possible without taking these variances into consideration. For deal with this case, Authors in [22] proposed an analytic hierarchy process-based approach for dealing with this problem as a MCDM problem and experimentally validated their approach using information security data. However, their approach is not ideal in this situation for two main reasons. The analytic hierarchy process method does not deal with the uncertainty involved in assessing the importance of the factors of an MCDM problem and the organizational health literacy responsiveness level of companies; additionally, their approach is used as a single qualitative preference point measurement scale for capturing the evaluation data, and this approach is sometimes not accurately expressed in the case being assessed [23-25]. Additionally, it does not deal with the vague assessment situation. The uncertainty problem occurred through the evaluation process because of a lack of information or imprecision related to the decision making values and judgments [24]. Fuzzy based MCDM approaches are accomplished of demonstrating this vagueness and dealing with its fuzzy situations [23-25].

In any case, analysis of worldwide and locally observational studies observed that studies that have addressed a structured comparison of the organizational health literacy responsiveness (OHLR) level of a healthcare organization and the comparative analysis of MCDM models to each other in health literacy applications do not exist; on the second hand, the available reviews provide a non-fuzzy model for structured comparison purposes [22], and as it was early explained, this model is not the suitable to solve the structured comparison problem under uncertainty conditions.

On the other hand, in addition to the fact that the qualitative methods proposed in that study are not ideal in evaluating the level of application, and the inability of the traditional qualitative - AHP integrated method to solve the problem of ambiguity related to evaluation, there is another problem, their model [22] in the last structured comparison step relied on a single scale to map the evaluation results of investigated alternatives to the relevant comparison scale for all objectives, and this of course generates inaccurate comparison results, especially if the differences in the evaluation scores between the alternatives are small.

Therefore, this study addresses to reduce this gap attempting to describe how to structurally compare the health literacy performance of healthcare organizations in a specific health sector (or sub-healthcare organization of a particular 
organization in the healthcare sector) under an uncertain environment and taking into account the sustainable priorities of this sector and the varying importance of the evaluation factors. It also aims to develop a fuzzy based framework to solve this problem.

The remainder of this paper is organized as follows. In Section 2 a brief overview of the related work was provided. Section 3 described our methodology. The results are shown in Section 4, followed by a discussion and conclusion in Section 5 and Section 6, respectively.

\section{RELATED WORK AND LITERATURE REVIEW}

\section{A. The Potential of Health Literacy to Address the Related UN Sustainable Development Goals}

Ensuring healthy lives and promoting well-being at all ages is the main health goal among the 2030 - sustainable development Goals [26]. The sustainable development G numbers $1,2,4,8$, and 10 are also allied to health and will contribute to the enhancement of the health of the overall population [27]. Knowledge and education, culture, gender roles, and quality, and cost of services effect the stakeholders to access services, engage with them and enact decisions that represent a group of healthcare engagement barriers [28, 29]. The knowledge of services; hazards; problems with services, availability, and quality; and health system responsiveness are of highly priority and considerable sustainable development goal targets for dealing with such challenges [29]. Making sound decisions about the health of the overall population and public health promotion is a basic requirement to improve and maintain the quality of life in society, and this requirement cannot be achieved without the availability of characteristics, skills, competence, and motivation among individuals who work in health information and services. The availability of these features, without the necessary support to access this information and these services, understand, and use them also hinders the achievement of these goals. These two factors are directly linked to health literacy, and the integration of these factors to achieve this requirement in the scope of one system summarizes the concept of health literacy [28] .Accordingly, health literacy is a pivotal determinant of discernment, reaching, and benefitting health data and services and strongly supports achieving the 2030 goals and targets. It is important that the health literacy needs of the community are directed and that measures for improving it are selected, adjusted, and implemented. To achieve this, the health literacy responsiveness should be considered, assessed, and improved $[10,28]$, and diagnosis of the actual status of health literacy is a basic step for achieving that [10].

\section{B. The Corporate Social Responsibility, Sustainable Development and Health Literacy}

Lately, the interaction between the conceptions of corporate social responsibility and sustainable development has consolidated, and sustainable development is considered an integrated community project. It works to achieve community security by focusing on the main components, which are environmental security, social security, and economic security, to protect society from environmental, social, and economic risks that threaten its security and stability [30, 31]. Therefore, all segments of society must participate in it. All governments, private sector companies, and institutions, and civil society organizations should participate and contribute to raising the level of societies by adopting social responsibility initiatives that are in line with development goals. Corporate responsibility and corporate sustainability can be used as synonyms (United Nations Global Compact, 2013). Both the corporate social responsibility and the sustainable development are based on the same dimensions that ultimately lead to achieving their goals in societies [31]. Both corporate social responsibility and sustainable development are highly contextual in terms of their temporal and societal setting. They are both subject to issue attention cycles in which events or findings give them urgency, and organizations respond and adapt [31]. Pesmatzoglou [32] estimates that there are absolutely no development goals that social responsibility cannot contribute to. Thus, the aforementioned social and health challenges and the consequences of economic problems that fall within the objectives of sustainable development, can be processed by addressing and increasing corporate social responsibility. However, to improve health literacy, corporate social responsibility decision makers should focus on [33]: (1) integrating health literacy initiatives into existing corporate social responsibility programs focused on health and wellbeing in the workplace; (2) engaging in an active dialogue with key healthcare stakeholders; and (3) developing a "Blueprint for Action in Health Literacy," based on best practices and case studies. Companies and programs that are moving toward enhancing their social role in society will be able to solve many problems by assessing the current organizational health literacy responsiveness situation of healthcare organizations, knowing and arranging the different areas and weaknesses of health literacy in organizations according to the sustainable development priorities of the health sector, and focusing on these points and creating partnerships between health institutions and the institutions. The most prominent is that the investment in dedicated resources will be distributed in accordance with sustainable health priorities, and the supported corporate social responsibility programs and services will differ from one region to another and from one health organization to another, in accordance to the actual needs of the citizens benefiting from its services. In turn, these conflicts with sustainable health goals will lead to poor health sustainable situation [33].

\section{The Fuzzy Analytic Hierarchy Process}

The Hierarchy Analysis Process (AHP) is the most common and widely used method to derive relative weights of criteria. The analytic hierarchy process was developed by Saaty [34]. In practice, the process of analytic hierarchy process implementation requires two main stages to structure problems and derive priorities and importance through two comparison processes. In the first stage, the complex problem is divided into a hierarchy, while the second step begins with the prioritization procedure to determine the relative importance of the criteria at each level. In the last step, the hierarchical assessment is based on an indirect comparison of the decision maker's preferences, and the relative weights of each matrix are determined and normalized [35, 36]. The main feature of this approach is to turn a complex multidimensional 
problem into a one-dimensional problem and provide mechanisms for calculating the final standardized solution for multiple evaluation experts (combine the final choices of a group to agree on a single outcome). This method is flexible and capable to test irregularities. Also, it provides mechanisms for computing the expert consensus.

However, according to $[25,37]$ the traditional Satty's analytic hierarchy process method does not deal with the uncertainty involved in assessing the importance of the criteria For this reason, a fuzzy version of it was selected. This approach performs analytic hierarchy process under uncertainty and ambiguity, has received increasing acceptance, and has been approved and implemented to solve decision-making problems in many fields.

\section{Fuzzy Delphi based Assessment Method}

Several methodologies have been proposed in literature. Dalkey and Helmer [38] developed the classic Delphi method for surveying and consulting with experts, which is widely used for this purpose in numerous surveys over the last three decades. However, applying this method is still accompanied by some problems [39]: misinterpretation of expert views because of ignorance of the fuzzy variables; the need to repeat the assessment process, leading to a loss of specialist interest in progress assessment data, which makes the study more costly and systematically changes the original views. Another uncertainty problem occurred through the evaluation process because of a lack of information or imprecision. The fuzzy version of the Delphi method was developed to avoid such dilemmas. Application of this method reduces costs and time during the assessment of each item in the questionnaire, reduces the number of survey tours, increases the rate of retrieval of questionnaires, allows experts to express their opinions using fuzzy numbers, represents discretionary categories whose problem with fuzzy assessment disappears when used, provides a mechanism for dealing with nonconsensual cases accompanying the assessment, improves the integrity and consistency of opinions, and enhances expert consensus without opposing the original expert views on changes that contribute to a more realistic assessment of relevant problems and indicators [39].

\section{E. Assessment of the Organizational Health Literacy Responsiveness Level in Health Care Organizations}

Numerous healthcare organizations utilize an organizational health literacy responsiveness level estimation of the indicators from international standards to get a dependable measurement. Using this tool in accordance with specific requirements and guidelines is enough to get a picture of the situation in any organization and enough to make necessary improvements upon it. On the contrary, getting this picture at the branch level of any multi-branch hospital, or at the institutional level of the public or private sector, is still not enough to make a correct comparison between their different health literacy states. This is because different branches or institutions have different sustainable objectives, environments, and priorities; consequently, the importance of evaluation areas and processes also varies. These comparisons are needed to ensure the economical investment of company resources as well as to ensure a sustainable distribution for government services and resources that support improving the situation as well as the resources for enterprises supporting the sustainability of the health status as a type of social responsibility. As equitable and sustainable distribution requires an answer on where and to whom economic resources should be distributed to achieve the maximum possible benefits, this could be determined by the structured comparison assessment through adapting suitable methods.

Several evaluation frameworks and tools have been developed, collected, and tested-most notably those presented in [10, 41-42]. In this paper, we will use the international assessment tool of the HPH and HLO Working Groups - 2019 [10] because this tool is shown to be mature, widespread, and globally recognized. It is suitable for application in institutions of different sizes, with different levels of application, even if these institutions do not have previous experience in this regard. The assessment tool is designed so that it can be adapted to suit different international contexts and can be used as a comprehensive evaluation tool or, partly, through the selection of a brief set of its criteria and indicators, to assess the aspects that suit particular environments. The adaptation of such a tool minimizes the additional effort for collecting the required metrics.

Despite the different methods and procedures used to measure the actual level of literacy requirements, and despite the different tools used, the reviewed and applied research can be classified in this regard into four types. The first type is focused on measuring the level of adherence to literacy practices according to specific factors for the purpose of identifying and improving weaknesses in a specific healthcare institution [43] or in a group of institutions [44-46]. The second type is focused on measuring the relative importance of the areas and indicators of applying literacy practices for the purpose of determining the most important or most appropriate factors for the institution or a specific health sector [47]. However, there is an applied research gap around the third and fourth types. The third framework is focused on merging the previous two types into a single evaluation framework with the aim of evaluating the actual level of practices and taking into account the importance of various evaluation indicators and factors. A number of studies have used this framework but in other application domains [25]. Additionally, the fourth type uses additional tools called ranking tools to make comparisons between different institutions in terms of their general or indicator level of application for certain applied practices $[8,9]$. In any case, the comparison process in the fourth type requires the presence of two main inputs, the first input is the relative weight (relative importance) of the decision factors and indicators, and the second input is the result of the evaluation process. In practical terms, the applied study closest to our study is the one presented by Schmid [20], and it agrees in terms of the general objective and the methodological steps it followed, but it differs in other respects: (1) the field of application, Schmidt's study addressed the structured comparison of the information security maturity level of organizations, while this study focuses on the structured comparison of an organizational health literacy responsiveness Level in 
hospitals and (2) the method used to evaluate the importance of the criteria, Schmidt's study applied the analytic hierarchy process method, this technique is not ideal as explained in the introduction, for this reason the Fuzzy analytic hierarchy processes applied in this study and (3) the 5-point scoring qualitative method was applied for evaluation of the performance level in the Schmidt's study, this method is not deal with the foggy environmental problems of the evaluation, for this reason in this study the fuzzy Delphi method is used. Additionally, this study differs from the studies on literacy assessment in that we use tools to assess the actual reality of literacy practices based on fuzzy techniques that diminish the ambiguities and flaws of the first and second assessment types, which we referred to earlier in the introduction, by relying on the fuzzy Delphi and fuzzy analytic hierarchy process methods. It compares the relative importance of the organizational health literacy responsiveness indicators in terms of their relevance and appropriateness for achieving the sustainable objectives of health institutions.

Additionally, it also differs from all previous studies in that the proposed model does not use to measure the organizational health literacy responsiveness level of hospitals only, but, instead, uses to analyze and compare the cases of implementation between these hospitals according to each indicator and under the ambiguous conditions of the assessment. It also relied on multi-measurement scale to link the evaluation results with the structured comparison scale, in order to obtain more accurate comparative results.

\section{Structured Comparison ApPliCATION AND Model DESIGN}

Based on the previously review of the dissimilar assessment tools and approaches, qualitative and quantitative assessment methods, and fuzzy and non-fuzzy weighting methods that have been presented in the literature, the model design implemented in this study is presented through the following stages:

- Defining the general requirements for the implementation of the proposed model.

- Process chart design for the model by integrating the requirements of the international assessment tool of the $\mathrm{HPH}$ and HLO Working Groups, fuzzy AHP, and fuzzy Delphi methods.

- Criteria selection which is used for pairwise comparison by the experts and matrices development.

- Different rules and procedures that are provided in the literature using MCDMs in order to practically implement the proposed model.

\section{A. Requirements of the Proposed Model}

This framework could be used in general or as a specific framework. The following are required: (1) To achieve a good picture of the importance of health literacy criteria from the sustainable perspective of the country, the healthcare sustainable conditions in its different areas and the role of the selected healthcare facility in achieving it should be considered; (2) The importance of the criteria is deferent by cities and healthcare facility types (hospital, unit, or center and public or private), and this deference should also be considered; (3) The investigated and compared healthcare organizations should be located at the same location, and have the same facility type; (4) The selected indicators should be applicable for use in the selected sector [10]; (5) The information gathering should be repeatable and stable, and the consistency test for the data gathered should use fuzzy analytic hierarchy process data, and an agreement test for the decision makers' opinions gathered using fuzzy Delphi should be performed; and (6) The framework should allow the healthcare sector or companies to visualize and explain the results of the evaluation, weighting, and comparison and, finally, allow a derivation of the areas where the government or companies could improve or where the business sector could help, serve, or plan its corporate social responsibility practices.

\section{B. Model Design}

In order to design the desired model taking into account the functional requirements of it and based on the procedural requirements of the international assessment tool of the HPH and HLO Working Groups, fuzzy AHP, and fuzzy Delphi methods, more than thirty articles using fuzzy hybrid methodologies were studied. Therefore, Fig. 1 is the process chart for design the model of this study, it uses for forming interrelationships between the structured comparison requirements, OHLR criteria and indicators, the calculation of the local and global weights of them, and the aggregation and testing the consistency of the fuzzy scores, and classification, ranking of criteria, and structurally comparing of hospitals, respectively. The detailed explanation of the model will be displayed in the next two sections.

\section{Criteria Selection which is used for Pairwise Comparison by the Experts and Matrices Development}

The SAT-OHL-Hos-v1.0-EN-international tool [10] is used to select criteria and sub criteria, which is divided into 8 standards, 23 sub standards, and 156 indicators. For simplicity, the fourth standard was selected as a case study example. The fourth standard of this tool is devoted to measuring the application level of organizational health literacy responsiveness in providing and supporting easy navigation and access to documents, materials, and services. Its sub standards are: (C4-1) the organization enables first contact via user-friendly website and phone; (C4-2) the organization provides the information necessary for patients and visitors to get to the organization; (C4-3) Support is available to help patients and visitors navigate to the hospital; and (C4-4) Health information for patients and visitors is easy-to-understand and available for free. Taking requirement number 4 into consideration, and by interviewing 10 experts, 22 indicators were selected as an applicable measurement indicator for organizational health literacy responsiveness assessment. Table I shows these indicators and their distribution, while the final decision tree of the problem is presented in Fig. 2. 


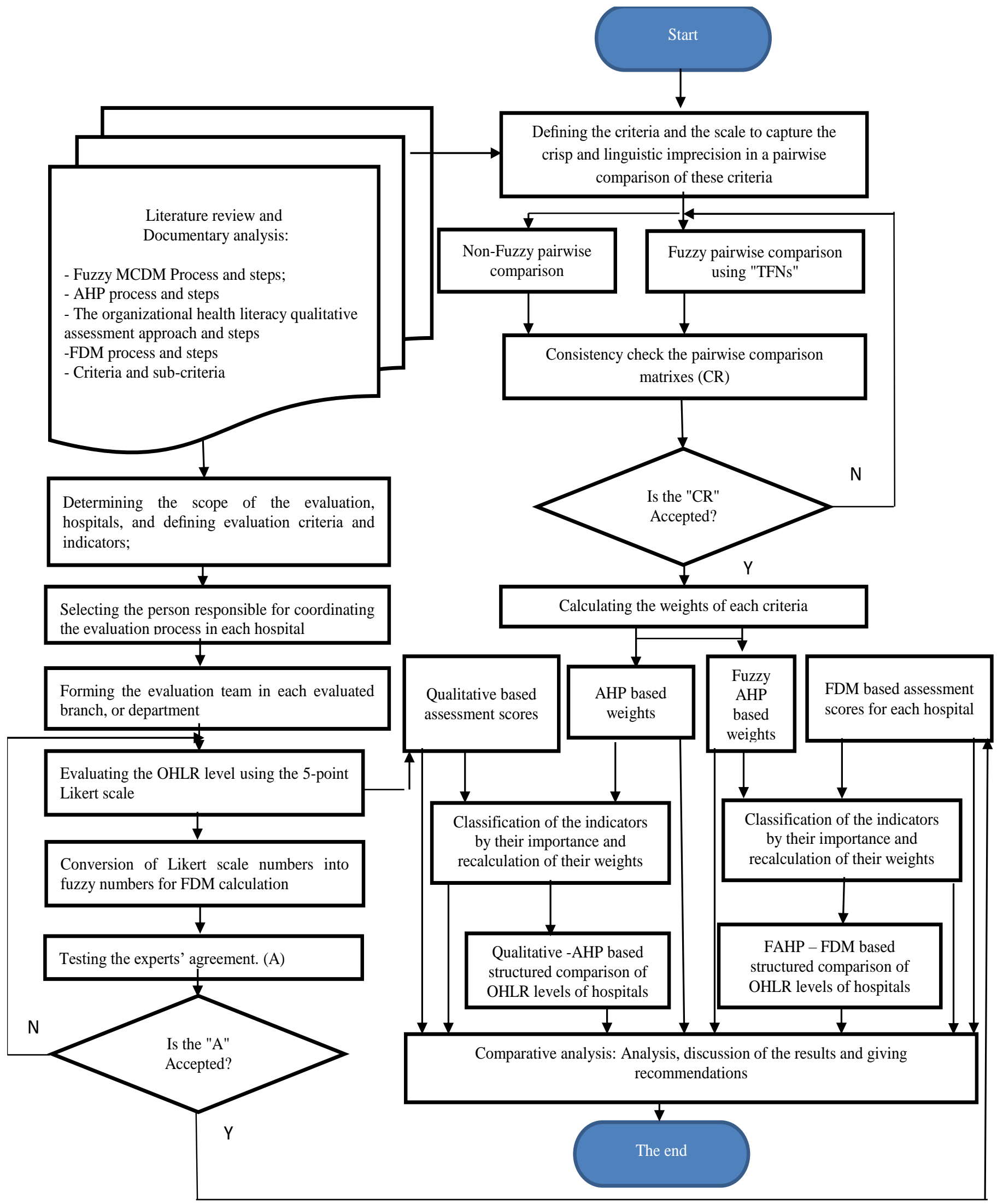

Fig. 1. Process Chart of the Model Design. 
TABLE I. OHLR INDICATORS OF THE FOURTH HLO STANDARD

\begin{tabular}{|c|c|}
\hline Indicator & Statement \\
\hline C4-1-1 & $\begin{array}{l}\text { The organization can easily be reached by telephone } 24 \text { hours a } \\
\text { day by an automated system and by a person. }\end{array}$ \\
\hline C4-1-2 & $\begin{array}{l}\text { If there is an automated phone system, there is a clear option to } \\
\text { repeat the menu items. }\end{array}$ \\
\hline C4-1-3 & $\begin{array}{l}\text { People at a hotline or an information desk are qualified to } \\
\text { adequately answer patient inquiries. }\end{array}$ \\
\hline C4-1-4 & $\begin{array}{l}\text { Contact information, location, and arrival information is easy-to- } \\
\text { find via Internet search engines. }\end{array}$ \\
\hline C4-1-5 & $\begin{array}{l}\text { The website is easy-to-use for people with low digital HL and/or } \\
\text { low HL. }\end{array}$ \\
\hline C4-1-6 & $\begin{array}{l}\text { The website provides evidence-based information on frequent } \\
\text { treatments and cites the scientific sources appropriately. }\end{array}$ \\
\hline C4-2-1 & $\begin{array}{l}\text { The naming of locations on maps is consistent with the terms or } \\
\text { wording used. }\end{array}$ \\
\hline $\mathrm{C} 4-2-2$ & $\begin{array}{l}\text { The healthcare organization provides patients with easy-to- } \\
\text { understand information about directions from the patient's home, } \\
\text { including public and private transportation options. }\end{array}$ \\
\hline C4-2-3 & $\begin{array}{l}\text { The healthcare organization negotiates with local transportation } \\
\text { services to assist patients by displaying adequate signage, clear } \\
\text { announcements, and location information at public } \\
\text { transportation stations. }\end{array}$ \\
\hline $\mathrm{C} 4-2-4$ & Admission departments are clearly marked and visible. \\
\hline C4-3-1 & $\begin{array}{l}\text { An information desk is available at all main entrances to support } \\
\text { navigation. }\end{array}$ \\
\hline $\mathrm{C} 4-3-2$ & Printed maps are available for free to support navigation. \\
\hline $\mathrm{C} 4-3-3$ & $\begin{array}{l}\text { Maps clearly indicate the individual's location through easy-to- } \\
\text { understand symbols or "You are here" signage. }\end{array}$ \\
\hline C4-3-4 & $\begin{array}{l}\text { The staff responsible for the admission of patients appropriately } \\
\text { directs patients and visitors to their respective unit and staff. }\end{array}$ \\
\hline $\mathrm{C} 4-3-5$ & $\begin{array}{l}\text { The signage design is based on the appropriate height, location, } \\
\text { color, and font size. }\end{array}$ \\
\hline C4-3-6 & $\begin{array}{l}\text { Consistent wording and use of symbols is applied to all locations } \\
\text { and rooms within the organization. }\end{array}$ \\
\hline C4-4-1 & $\begin{array}{l}\text { Patients are informed about deductibles or other costs for } \\
\text { treatment or services in advance. }\end{array}$ \\
\hline $\mathrm{C} 4-4-2$ & Patients are informed about their patient rights. \\
\hline C4-4-3 & $\begin{array}{l}\text { A physical or virtual patient information center comprising free } \\
\text { health information is available. }\end{array}$ \\
\hline C4-4-4 & $\begin{array}{l}\text { Various formats of easy-to-understand information regarding } \\
\text { disease prevention are available. }\end{array}$ \\
\hline C4-4-5 & $\begin{array}{l}\text { Various formats of easy-to-understand information regarding } \\
\text { healthy lifestyles are available at multiple locations for free. }\end{array}$ \\
\hline C4-4-6 & $\begin{array}{l}\text { Easy-to-understand menu information is available at bedside and } \\
\text { in the cafeteria or canteen indicating nutrients and calories to } \\
\text { support healthy choices. }\end{array}$ \\
\hline
\end{tabular}

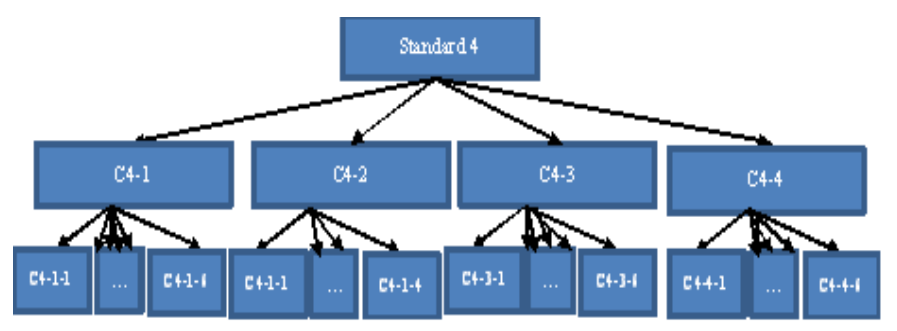

Fig. 2. The Decision Tree of the Problem.

\section{THE PROPOSED ALGORITHM AND ITS IMPLEMENTATION: DEMO APPLICATION}

1) First Stage: Weighting criteria and indicators by the fuzzy analytic hierarchy process.

In this study, the fuzzy analytic hierarchy process steps will be used as follows:

a) Step 1 -Defining the criteria (Section III.B).

b) Step 2-Defining the scale. This step captures the linguistic imprecision in a pairwise comparison of the criteria and indicators. Because the proposed framework considers the subjectivity, uncertainty, and ambiguity of experts' judgments, a fuzzy linguistic approach analog to the 9-point scale conceived by Saaty [34] should be used (Table II).

TABLE II. TRIANGULAR FUZZY CONVERSION SCALE

\begin{tabular}{|l|l|l|}
\hline $\begin{array}{l}\text { Level of } \\
\text { Importance }\end{array}$ & Linguistic & $\begin{array}{l}\text { The Scale of the } \\
\text { Fuzzy Number }\end{array}$ \\
\hline 9 & Absolute preference & $(8,9,10)$ \\
\hline 8 & $\begin{array}{l}\text { Preference between very strong and } \\
\text { absolute }\end{array}$ & $(7,8,9)$ \\
\hline 7 & Very strong preference & $(6,7,8)$ \\
\hline 6 & $\begin{array}{l}\text { Preference between strong and very } \\
\text { strong }\end{array}$ & $(5,6,7)$ \\
\hline 5 & Strong preference & $(4,5,6)$ \\
\hline 4 & Preference between moderate and strong & $(3,4,5)$ \\
\hline 3 & Moderate & $(2,3,4)$ \\
\hline 2 & $\begin{array}{l}\text { Preference between the equal and } \\
\text { moderate }\end{array}$ & $(1,2,3)$ \\
\hline 1 & Equal & $(1,1,1)$ \\
\hline
\end{tabular}

c) Step 3-Building the fuzzy pairwise comparison matrix.

This step shows the preference of one criterion over the other for prioritization of all of the criteria and sub criteria. This represents the domain specific part of the fuzzy analytic hierarchy process calculations, and it only needs to be done once per substandard. The characteristics of the healthcare facility type (hospital, unit, or center and public or private) and their locations have a significant influence on the pairwise comparison when the individual indicators are compared. This is because the sustainability healthcare priorities in different locations of the country are not the same, and the sustainability, responsibility, and functionality role of different types of organizations in each location are not equivalent. However, taking the first three requirements of comparison into consideration, the decision maker must compare each criterion with its pair and denote which of the two criteria appears more important to him/her. This method of pairwise comparison allows the decision maker to elicit a very precise evaluation from the multitude of competing criteria. The comparisons must be carried out for one healthcare sector (e.g., public hospitals in Sana'a). In the case of our hierarchy based on the organizational health literacy responsiveness indicators, 4 pairwise comparisons have to be made by each decision maker for the main HL's sub-categories and twenty two for the indicators based on four decision trees, 
respectively. For this study a number of 50 pairwise comparison matrixes were generated, these matrixes are generated the taking into account the consistently check conditions presented below.

d) Step 4-Consistency check the fuzzy pairwise comparison matrix and calculate the consistency ratio (CR). During this step, the consistency of the aggregate judgment matrix of all of the pairwise comparisons is determined by its consistency ratio (CR). To ensure a certain quality level for a decision, we have to analyze the consistency of the evaluation. To test the value of consistency of the comparison matrix depended on $n$, the consistency rate (CR) has to be computed. The CR is defined in [37] as a ratio between the consistency of a consistency index (CI) and the consistency of a random consistency index (RI). Saaty suggests that the consistency of the matrix is acceptable only if $\mathrm{CR}<0.10$ [37]. When a matrix is inconsistent, then new pairwise comparison judgments are required. Once the consistency ratio is accepted, it is possible to calculate the weights of the criteria.

e) Step 5-Calculating the weights of each criterion if the CR is accepted, then apply the change's fuzzy analytic hierarchy process procedures [48]. In our case study example, the CR were calculated and accepted. Table III represents the calculated $\mathrm{CR}$ values and the overall consensus rate (CR\%) for 10 decision makers (experts). While, Table IV represents the calculated weights and ranks of criteria based on F-AHP methods. It also represents the alternative calculated weights and ranks of criteria using the classical AHP method.

TABLE III. CR TESTING RESUlTS

\begin{tabular}{|c|c|c|c|c|c|c|c|c|c|c|c|}
\hline \multirow{2}{*}{ decision tree } & \multicolumn{10}{|c|}{ Expert } & \multirow{2}{*}{ CR $(\%)$} \\
\hline & $E X 1$ & $E X 2$ & $E X 3$ & EX4 & EX5 & EX6 & $E X 7$ & EX8 & EX9 & EX10 & \\
\hline $\mathrm{C} 4$ & 0.03 & 0.022 & 0.076 & 0.043 & 0.09 & 0.043 & 0.09 & 0.079 & 0.03 & 0.07 & 96.1 \\
\hline C4-1 & 0.02 & 0.086 & 0.08 & 0.031 & 0.073 & 0.061 & 0.08 & 0.09 & 0.05 & 0.03 & 97.8 \\
\hline $\mathrm{C} 4-2$ & 0.06 & 0.063 & 0.09 & 0.022 & 0.043 & 0.05 & 0.07 & 0.02 & 0.02 & 0.075 & 98 \\
\hline $\mathrm{C} 4-3$ & 0.026 & 0.084 & 0.08 & 0.08 & 0.081 & 0.063 & 0.08 & 0.09 & 0.091 & 0.06 & 96.9 \\
\hline C4-4 & 0.035 & 0.078 & 0.067 & 0.062 & 0.08 & 0.013 & 0.07 & 0.053 & 0.078 & 0.057 & 96.5 \\
\hline
\end{tabular}

TABLE IV. THE ORGANIZATIONAL HEALTH LITERACY RESPONSIVENESS INDICATORS, THEIR WEIGHTS AND RANKS

\begin{tabular}{|c|c|c|c|c|c|}
\hline \multirow[b]{2}{*}{$\mathrm{C}-\mathrm{N}$} & \multirow[b]{2}{*}{ Indicator } & \multicolumn{2}{|l|}{ FAHP } & \multicolumn{2}{|l|}{ AHP } \\
\hline & & Global Weight & Rank & Global Weight & Rank \\
\hline \multirow[t]{6}{*}{ C4-1 } & C4-1-1 & 0.029 & 13 & 0.034304 & 14 \\
\hline & C4-1-2 & 0.028 & 15 & 0.035584 & 12 \\
\hline & C4-1-3 & 0.030 & 12 & 0.043264 & 10 \\
\hline & C4-1-4 & 0.124 & 1 & 0.073472 & 3 \\
\hline & C4-1-5 & 0.044 & 11 & 0.040448 & 11 \\
\hline & C4-1-6 & 0.014 & 22 & 0.029184 & 17 \\
\hline \multirow[t]{4}{*}{$\mathrm{C} 4-2$} & C4-2-1 & 0.047 & 10 & 0.043554 & 9 \\
\hline & $\mathrm{C} 4-2-2$ & 0.052 & 6 & 0.053074 & 8 \\
\hline & C4-2-3 & 0.017 & 21 & 0.03451 & 13 \\
\hline & C4-2-4 & 0.121 & 2 & 0.106862 & 1 \\
\hline \multirow[t]{6}{*}{$\mathrm{C} 4-3$} & C4-3-1 & 0.026 & 17 & 0.027888 & 18 \\
\hline & C4-3-2 & 0.025 & 18 & 0.02772 & 19 \\
\hline & C4-3-3 & 0.022 & 19 & 0.022848 & 21 \\
\hline & C4-3-4 & 0.029 & 14 & 0.033768 & 15 \\
\hline & C4-3-5 & 0.028 & 16 & 0.030912 & 16 \\
\hline & C4-3-6 & 0.021 & 20 & 0.024696 & 20 \\
\hline \multirow[t]{6}{*}{ C4-4 } & C4-4-1 & 0.062 & 5 & 0.070616 & 4 \\
\hline & C4-4-2 & 0.071 & 3 & 0.076824 & 2 \\
\hline & C4-4-3 & 0.047 & 8 & 0.05626 & 7 \\
\hline & C4-4-4 & 0.065 & 4 & 0.069064 & 5 \\
\hline & C4-4-5 & 0.048 & 7 & 0.05626 & 7 \\
\hline & C4-4-6 & 0.047 & 9 & 0.057424 & 6 \\
\hline
\end{tabular}


2) Second stage: classification of the indicators by their importance and recalculation of their weights.

To compare the organizational health literacy responsiveness levels of the company for each importance category, the indicators should be classified into importance categories. In this study, four categories were defined and the importance of their indicators was recalculated. The weight of each indicator is calculated by the division of its global weight on the total weights of groups' indicators. Based on the results obtained from the first stage, four importance categories were defined (G1-G4), and the relative importance (LW) and the ranking order (NR) of their indicators were recalculated using FAHP and AHP as shown in Table V.

3) Third stage: Applying the organizational health literacy Assessment approach and the fuzzy Delphi method to determine the health literacy responsiveness level of the healthcare organization.

The methodology was used to measure the real situation according to this international standard, which can be summarized as follows [10]:

a) determining the scope of the evaluation and defining evaluation criteria and indicators; b) selecting the person responsible for coordinating the evaluation process, having the ability to coordinate and manage the process;

c) forming the evaluation team in each evaluated branch, or department. Between 5 and 10 experts from the following areas should be involved: management; quality management; health promotion; human resource development; medicine; nursing; therapeutic professions, preferably from different departments; building services engineering or maintenance; patient-ombudsman or woman; self-help and patient representatives, communications, or spokesperson;

d) evaluating the OHLR level, to capture the results and compare them, the 5 -point Likert scale $(1=$ very poor to $5=$ very good) is suggested for this process; and.

e) discussing the results in the next meeting, focusing on which assessment best describes the overall situation.

In this step, to determine the values that describe the overall situation on each indicator in each organization, the fuzzy Delphi method should be applied as follows [39]:

- conversion of Likert scale numbers into fuzzy numbers;

- defuzzification of the fuzzy scores; and

- testing the experts' agreement.

TABLE V. CLASSIFICATION OF OHLR INDICATORS BY THEIR IMPORTANCE CATEGORY

\begin{tabular}{|c|c|c|c|c|c|c|c|c|c|c|c|c|c|c|c|}
\hline \multirow[b]{2}{*}{ G } & \multicolumn{5}{|l|}{ F-AHP } & \multicolumn{5}{|l|}{ AHP } & \multirow[t]{2}{*}{ Indicator } & \multicolumn{2}{|l|}{ FAHP } & \multicolumn{2}{|l|}{ AHP } \\
\hline & Indicator & $\mathbf{W}$ & Rank & LW & LR & Indicator & $\mathbf{W}$ & Rank & LW & LR & & Order & Class & Order & Class \\
\hline \multirow[t]{5}{*}{ G1 } & C4-1-4 & 0.099 & 1 & 0.24 & 1 & C4-2-4 & 0.107 & 1 & 0.290 & 1 & C4-1-4 & 1 & 1 & 3 & 1 \\
\hline & C4-2-4 & 0.121 & 2 & 0.29 & 2 & C4-4-2 & 0.067 & 2 & 0.181 & 2 & C4-2-4 & 2 & 1 & 1 & 1 \\
\hline & C4-4-2 & 0.071 & 3 & 0.17 & 3 & C4-1-4 & 0.073 & 3 & 0.199 & 3 & C4-4-2 & 3 & 1 & 2 & 1 \\
\hline & C4-4-4 & 0.065 & 4 & 0.15 & 4 & C4-4-1 & 0.062 & 4 & 0.167 & 4 & C4-4-4 & 4 & 1 & 5 & 1 \\
\hline & C4-4-1 & 0.062 & 5 & 0.15 & 5 & C4-4-4 & 0.060 & 5 & 0.163 & 5 & C4-4-1 & 5 & 1 & 4 & 1 \\
\hline \multirow[t]{5}{*}{ G2 } & C4-2-2 & 0.052 & 6 & 0.22 & 1 & C4-4-6 & 0.050 & 6 & 0.206 & 1 & C4-2-2 & 6 & 2 & 8 & 2 \\
\hline & C4-4-5 & 0.048 & 7 & 0.2 & 2 & C4-4-3 & 0.049 & 7 & 0.200 & 2 & C4-4-5 & 7 & 2 & 7 & 2 \\
\hline & C4-4-3 & 0.047 & 8 & 0.2 & 3 & C4-4-5 & 0.049 & 7 & 0.200 & 2 & C4-4-3 & 8 & 2 & 7 & 2 \\
\hline & C4-4-6 & 0.047 & 9 & 0.19 & 4 & $\mathrm{C} 4-2-2$ & 0.053 & 8 & 0.217 & 3 & C4-4-6 & 9 & 2 & 6 & 2 \\
\hline & C4-2-1 & 0.047 & 10 & 0.19 & 5 & C4-2-1 & 0.044 & 9 & 0.178 & 4 & C4-2-1 & 10 & 2 & 9 & 2 \\
\hline \multirow[t]{6}{*}{ G3 } & C4-1-5 & 0.044 & 11 & 0.2 & 1 & C4-1-3 & 0.043 & 10 & 0.195 & 1 & C4-1-5 & 11 & 3 & 11 & 3 \\
\hline & C4-1-3 & 0.054 & 12 & 0.25 & 2 & C4-1-5 & 0.040 & 11 & 0.182 & 2 & C4-1-3 & 12 & 3 & 10 & 3 \\
\hline & C4-1-1 & 0.029 & 13 & 0.14 & 3 & C4-1-2 & 0.036 & 12 & 0.160 & 3 & C4-1-1 & 13 & 3 & 14 & 3 \\
\hline & C4-3-4 & 0.029 & 14 & 0.13 & 4 & C4-2-3 & 0.035 & 13 & 0.156 & 4 & C4-3-4 & 14 & 3 & 15 & 3 \\
\hline & C4-1-2 & 0.032 & 15 & 0.15 & 5 & C4-1-1 & 0.034 & 14 & 0.155 & 5 & C4-1-2 & 15 & 3 & 12 & 3 \\
\hline & C4-3-5 & 0.028 & 16 & 0.13 & 6 & C4-3-4 & 0.034 & 15 & 0.152 & 6 & C4-3-5 & 16 & 3 & 16 & 4 \\
\hline \multirow[t]{6}{*}{ G4 } & C4-3-1 & 0.026 & 17 & 0.21 & 1 & C4-3-5 & 0.031 & 16 & 0.189 & 1 & C4-3-1 & 17 & 4 & 18 & 4 \\
\hline & C4-3-2 & 0.025 & 18 & 0.2 & 2 & C4-1-6 & 0.029 & 17 & 0.179 & 2 & C4-3-2 & 18 & 4 & 19 & 4 \\
\hline & C4-3-3 & 0.022 & 19 & 0.18 & 3 & C4-3-1 & 0.028 & 18 & 0.171 & 3 & C4-3-3 & 19 & 4 & 21 & 4 \\
\hline & C4-3-6 & 0.021 & 20 & 0.17 & 4 & C4-3-2 & 0.028 & 19 & 0.170 & 4 & C4-3-6 & 20 & 4 & 20 & 4 \\
\hline & $\mathrm{C} 4-2-3$ & 0.017 & 21 & 0.14 & 5 & C4-3-6 & 0.025 & 20 & 0.151 & 5 & C4-2-3 & 21 & 4 & 13 & 3 \\
\hline & C4-1-6 & 0.014 & 22 & 0.11 & 6 & C4-3-3 & 0.023 & 21 & 0.140 & 6 & C4-1-6 & 22 & 4 & 17 & 4 \\
\hline
\end{tabular}


The procedures in the last step should be repeated for each investigated indicator for each organization. The number of experts should be optimal and comply with the previous suggestions for the Delphi method implementation, which are between ten and fifty [49]. In this study, 10 evaluators were selected as an evaluation team in each organization, and this number is optimal and complied with both the Delphi [49] and organizational health literacy assessment tool requirement [10]. The triangular fuzzy numbers provided an opportunity for each recorded response made by an expert in the form of the Likert-scale scoring to be translated into fuzzy scoring (refer to Table VI. After that, the fuzzy scores should be averaged for the defuzzification process. This process is to identify the organizational health literacy responsiveness level of the organization on each indicator. In the last step, the experts' agreement (expert consensus) should be calculated and must be $\geq 75 \%$ [36/145]. If this condition is not achieved, the fourth and fifth evaluation processes should be repeated. Table VI was used for mapping the averaged fuzzy scores to their relevant organizational health literacy responsiveness levels. Section 4 describes the obtained results. In this study the experts' consensus equaled $100 \%$ for each indicator in all three virtual organizations of the case study example. The OHLR level of hospitals based on both qualitative-AHP based model and FDM_FAHP methods are presented in Table VII, and Table VIII, respectively. After that, to simplify the comparison process of the results, these score were represented in percentage form, and the practical gaps in the implementation of the OHLR practices for each alternative hospital were also calculated.

After that, the overall weighted evaluation scores of hospitals based on both models on each main original category (C4-1-C4-4), and on the whole (C4) standard were calculated, these values were also mapped into the percentage scale as well. Tables IX, and X represent the results. In addition, the overall weighted evaluation scores of hospitals based on both models on each importance category (G1-C4) were calculated. These values were also mapped into the percentage gap scale. Tables XI and XII represent the result.

TABLE VI. FUZZY DELPHI EVALUATION SCALES AND ASSESSMENT INDEX

\begin{tabular}{|l|l|l|l|l|}
\hline \multirow{2}{*}{ Likert Scale } & \multirow{2}{*}{ Linguistic Variable } & \multicolumn{3}{|l|}{ Fuzzy Scale } \\
\cline { 3 - 5 } & & $\boldsymbol{n 1}$ & $\boldsymbol{n 2}$ & $\boldsymbol{n 3}$ \\
\hline 5 & Very good (VG) & 0.6 & 0.8 & 1 \\
\hline 4 & Good (G) & 0.4 & 0.6 & 0.8 \\
\hline 3 & Fair (F) & 0.2 & 0.4 & 0.6 \\
\hline 2 & Poor (P) & 0 & 0.2 & 0.4 \\
\hline 1 & Very poor (VP) & 0 & 0 & 0.2 \\
\hline
\end{tabular}

TABLE VII. The QuAlitative - AHP BASED Evaluation Results

\begin{tabular}{|c|c|c|c|c|c|c|c|c|c|c|c|c|c|}
\hline \multirow[b]{2}{*}{ G } & \multirow{2}{*}{ Indicator } & \multirow{2}{*}{$\mathbf{L W}$} & \multirow{2}{*}{ local rank } & \multicolumn{3}{|l|}{ ES } & \multicolumn{3}{|c|}{ ES \% } & \multicolumn{3}{|c|}{ Gap } & \multirow[b]{2}{*}{ Max-Gap } \\
\hline & & & & H1 & H2 & H3 & H1 & H2 & H3 & H1 & H2 & H3 & \\
\hline \multirow[t]{5}{*}{ G1 } & C4-2-4 & 0.290 & 1 & 4.3 & 4.6 & 4.7 & 86 & 92 & 94 & 14 & 8 & 6 & 14 \\
\hline & C4-4-2 & 0.181 & 2 & 1.4 & 2.7 & 2.6 & 28 & 54 & 52 & 72 & 46 & 48 & 72 \\
\hline & C4-1-4 & 0.199 & 3 & 1.2 & 1.5 & 1.6 & 24 & 30 & 32 & 76 & 70 & 68 & 76 \\
\hline & C4-4-1 & 0.167 & 4 & 4.4 & 4.4 & 4.5 & 88 & 88 & 90 & 12 & 12 & 10 & 12 \\
\hline & C4-4-4 & 0.163 & 5 & 2.6 & 2.7 & 2.8 & 52 & 54 & 56 & 48 & 46 & 44 & 48 \\
\hline \multirow[t]{5}{*}{ G2 } & C4-4-6 & 0.206 & 1 & 4.2 & 4.5 & 4.6 & 84 & 90 & 92 & 16 & 10 & 8 & 16 \\
\hline & C4-4-3 & 0.200 & 2 & 2.4 & 2.8 & 2.9 & 48 & 56 & 58 & 52 & 44 & 42 & 52 \\
\hline & C4-4-5 & 0.200 & 2 & 4.1 & 4.3 & 4.5 & 82 & 86 & 90 & 18 & 14 & 10 & 18 \\
\hline & C4-2-2 & 0.217 & 3 & 3.2 & 3.2 & 3.3 & 64 & 64 & 66 & 36 & 36 & 34 & 36 \\
\hline & C4-2-1 & 0.178 & 4 & 3.2 & 3.6 & 3.8 & 64 & 72 & 76 & 36 & 28 & 24 & 36 \\
\hline \multirow[t]{6}{*}{ G3 } & C4-1-3 & 0.195 & 1 & 3.3 & 3.7 & 3.8 & 66 & 74 & 76 & 34 & 26 & 24 & 34 \\
\hline & C4-1-5 & 0.182 & 2 & 1 & 1.3 & 1.5 & 20 & 26 & 30 & 80 & 74 & 70 & 80 \\
\hline & C4-1-2 & 0.160 & 3 & 1 & 1.2 & 1.5 & 20 & 24 & 30 & 80 & 76 & 70 & 80 \\
\hline & C4-2-3 & 0.156 & 4 & 3.6 & 3.8 & 3.6 & 72 & 76 & 72 & 28 & 24 & 28 & 28 \\
\hline & C4-1-1 & 0.155 & 5 & 3.2 & 3.7 & 3.8 & 64 & 74 & 76 & 36 & 26 & 24 & 36 \\
\hline & C4-3-4 & 0.152 & 6 & 4.7 & 4.9 & 4.6 & 94 & 98 & 92 & 6 & 2 & 8 & 8 \\
\hline \multirow[t]{6}{*}{ G4 } & C4-3-5 & 0.189 & 1 & 4.8 & 4.8 & 4.9 & 96 & 96 & 98 & 4 & 4 & 2 & 4 \\
\hline & C4-1-6 & 0.179 & 2 & 1 & 1 & 1.1 & 20 & 20 & 22 & 80 & 80 & 78 & 80 \\
\hline & C4-3-1 & 0.171 & 3 & 3.4 & 3.7 & 3.6 & 68 & 74 & 72 & 32 & 26 & 28 & 32 \\
\hline & C4-3-2 & 0.170 & 4 & 2.3 & 2.7 & 2.8 & 46 & 54 & 56 & 54 & 46 & 44 & 54 \\
\hline & C4-3-6 & 0.151 & 5 & 4.9 & 4.9 & 4.9 & 98 & 98 & 98 & 2 & 2 & 2 & 2 \\
\hline & C4-3-3 & 0.140 & 6 & 4.6 & 4.8 & 4.8 & 92 & 96 & 96 & 8 & 4 & 4 & 8 \\
\hline
\end{tabular}


TABLE VIII. THE FDM-FAHP BASED EVALUATION SCORES

\begin{tabular}{|c|c|c|c|c|c|c|c|c|c|c|c|c|c|}
\hline \multirow[b]{2}{*}{ G } & \multirow{2}{*}{ Indicator } & \multirow{2}{*}{ LW } & \multirow{2}{*}{ LR } & \multicolumn{3}{|l|}{ ES } & \multicolumn{3}{|l|}{ ES \% } & \multicolumn{3}{|l|}{ Gap } & \multirow[b]{2}{*}{ Max-Gap } \\
\hline & & & & H1 & H2 & $\mathbf{H 3}$ & H1 & H2 & H3 & H1 & H2 & H3 & \\
\hline \multirow[t]{5}{*}{ G1 } & C4-1-4 & 0.24 & 1 & 0.09 & 0.13 & 0.15 & 11.63 & 16.63 & 18.38 & 88.38 & 83.38 & 81.63 & 88.38 \\
\hline & C4-2-4 & 0.29 & 2 & 0.66 & 0.72 & 0.74 & 82.50 & 90.00 & 92.50 & 17.50 & 10.00 & 7.50 & 17.50 \\
\hline & C4-4-2 & 0.17 & 3 & 0.12 & 0.34 & 0.32 & 15.00 & 42.50 & 40.00 & 85.00 & 57.50 & 60.00 & 85.00 \\
\hline & C4-4-4 & 0.15 & 4 & 0.32 & 0.34 & 0.36 & 40.00 & 42.50 & 45.00 & 60.00 & 57.50 & 55.00 & 60.00 \\
\hline & C4-4-1 & 0.15 & 5 & 0.68 & 0.68 & 0.70 & 85.00 & 85.00 & 87.50 & 15.00 & 15.00 & 12.50 & 15.00 \\
\hline \multirow[t]{5}{*}{ G2 } & C4-2-2 & 0.22 & 1 & 0.44 & 0.44 & 0.46 & 55.00 & 55.00 & 57.50 & 45.00 & 45.00 & 42.50 & 45.00 \\
\hline & C4-4-5 & 0.20 & 2 & 0.62 & 0.66 & 0.70 & 77.50 & 82.50 & 87.50 & 22.50 & 17.50 & 12.50 & 22.50 \\
\hline & C4-4-3 & 0.20 & 3 & 0.28 & 0.36 & 0.38 & 35.00 & 45.00 & 47.50 & 65.00 & 55.00 & 52.50 & 65.00 \\
\hline & C4-4-6 & 0.19 & 4 & 0.64 & 0.70 & 0.72 & 80.00 & 87.50 & 90.00 & 20.00 & 12.50 & 10.00 & 20.00 \\
\hline & C4-2-1 & 0.19 & 5 & 0.44 & 0.52 & 0.56 & 55.00 & 65.00 & 70.00 & 45.00 & 35.00 & 30.00 & 45.00 \\
\hline \multirow[t]{6}{*}{ G3 } & C4-1-5 & 0.20 & 1 & 0.07 & 0.11 & 0.14 & 8.38 & 14.13 & 17.50 & 91.63 & 85.88 & 82.50 & 91.63 \\
\hline & C4-1-3 & 0.25 & 2 & 0.46 & 0.54 & 0.56 & 57.50 & 67.50 & 70.00 & 42.50 & 32.50 & 30.00 & 42.50 \\
\hline & C4-1-1 & 0.14 & 3 & 0.44 & 0.54 & 0.56 & 55.00 & 67.50 & 70.00 & 45.00 & 32.50 & 30.00 & 45.00 \\
\hline & C4-3-4 & 0.13 & 4 & 0.74 & 0.78 & 0.72 & 92.50 & 97.50 & 90.00 & 7.50 & 2.50 & 10.00 & 10.00 \\
\hline & C4-1-2 & 0.15 & 5 & 0.07 & 0.09 & 0.13 & 8.38 & 11.63 & 16.63 & 91.63 & 88.38 & 83.38 & 91.63 \\
\hline & C4-3-5 & 0.13 & 6 & 0.76 & 0.76 & 0.78 & 95.00 & 95.00 & 97.50 & 5.00 & 5.00 & 2.50 & 5.00 \\
\hline \multirow[t]{6}{*}{ G4 } & C4-3-1 & 0.21 & 1 & 0.48 & 0.54 & 0.52 & 60.00 & 67.50 & 65.00 & 40.00 & 32.50 & 35.00 & 40.00 \\
\hline & C4-3-2 & 0.20 & 2 & 0.26 & 0.34 & 0.36 & 32.50 & 42.50 & 45.00 & 67.50 & 57.50 & 55.00 & 67.50 \\
\hline & C4-3-3 & 0.18 & 3 & 0.72 & 0.76 & 0.76 & 90.00 & 95.00 & 95.00 & 10.00 & 5.00 & 5.00 & 10.00 \\
\hline & C4-3-6 & 0.17 & 4 & 0.78 & 0.78 & 0.78 & 97.50 & 97.50 & 97.50 & 2.50 & 2.50 & 2.50 & 2.50 \\
\hline & C4-2-3 & 0.14 & 5 & 0.52 & 0.56 & 0.52 & 65.00 & 70.00 & 65.00 & 35.00 & 30.00 & 35.00 & 35.00 \\
\hline & C4-1-6 & 0.11 & 6 & 0.07 & 0.07 & 0.08 & 8.38 & 8.38 & 10.00 & 91.63 & 91.63 & 90.00 & 91.63 \\
\hline
\end{tabular}

TABLE IX. The Overall Weighted Evaluation SCOREs of HosPitals: Qualitative - AHP Model

\begin{tabular}{|c|c|c|c|c|c|c|c|c|c|c|c|c|}
\hline \multirow{2}{*}{ Category } & \multirow{2}{*}{$\mathbf{W}$} & \multirow{2}{*}{$\mathbf{R}$} & \multicolumn{3}{|c|}{ Weighted ES } & \multicolumn{3}{|c|}{ Weighted ES \% } & \multicolumn{3}{|l|}{ Gap } & \multirow[b]{2}{*}{ Max-Gap } \\
\hline & & & H1 & H2 & H3 & H1 & H2 & H3 & H1 & H2 & H3 & \\
\hline C4-1 & 0.256 & 3 & 3.148 & 3.499 & 3.565 & 62.950 & 69.982 & 71.308 & 37.050 & 30.018 & 28.692 & 37.050 \\
\hline $\mathrm{C} 4-2$ & 0.238 & 2 & 3.186 & 3.492 & 3.655 & 63.726 & 69.834 & 73.098 & 36.274 & 30.166 & 26.902 & 36.274 \\
\hline C4-3 & 0.168 & 4 & 3.030 & 3.257 & 3.281 & 60.590 & 65.146 & 65.614 & 39.410 & 34.854 & 34.386 & 39.410 \\
\hline C4-4 & 0.338 & 1 & 3.134 & 3.357 & 3.399 & 62.674 & 67.148 & 67.974 & 37.326 & 32.852 & 32.026 & 37.326 \\
\hline $\mathrm{C} 4$ & 1 & & 3.132 & 3.409 & 3.483 & 62.645 & 68.176 & 69.651 & 37.355 & 31.824 & 30.349 & 37.355 \\
\hline
\end{tabular}

TABLE X. The OVERALl Weighted Evaluation SCORES OF HosPitAls: FDM-FAHP Model

\begin{tabular}{|c|c|c|c|c|c|c|c|c|c|c|c|c|}
\hline \multirow{2}{*}{ Category } & \multirow{2}{*}{$\mathbf{W}$} & \multirow{2}{*}{$\mathbf{R}$} & \multicolumn{3}{|c|}{ Weighted ES } & \multicolumn{3}{|c|}{ Weighted ES \% } & \multicolumn{3}{|l|}{ Gap } & \multirow[b]{2}{*}{ Max-Gap } \\
\hline & & & H1 & H2 & H3 & H1 & H2 & H3 & H1 & H2 & H3 & \\
\hline $\mathrm{C} 4-1$ & 0.273 & 3 & 0.195 & 0.246 & 0.267 & 24.314 & 30.769 & 33.387 & 75.686 & 69.231 & 66.613 & 75.686 \\
\hline $\mathrm{C} 4-2$ & 0.237 & 2 & 0.558 & 0.608 & 0.627 & 69.790 & 75.965 & 78.428 & 30.210 & 24.035 & 21.573 & 30.210 \\
\hline C4-3 & 0.149 & 4 & 0.623 & 0.660 & 0.652 & 77.835 & 82.480 & 81.475 & 22.165 & 17.520 & 18.525 & 22.165 \\
\hline $\mathrm{C} 4-4$ & 0.341 & 1 & 0.425 & 0.500 & 0.514 & 53.123 & 62.475 & 64.283 & 46.878 & 37.525 & 35.718 & 46.878 \\
\hline $\mathrm{C} 4$ & 1 & & 0.423 & 0.480 & 0.494 & 52.890 & 59.997 & 61.762 & 47.110 & 40.003 & 38.238 & 47.110 \\
\hline
\end{tabular}


TABLE XI. ThE OVERALL WeIGHTED EVALUATION SCORES OF HOSPITALS ON IMPORTANCE Groups: QuALITATIVE- AHP MODEL

\begin{tabular}{|c|c|c|c|c|c|c|c|c|c|c|c|c|}
\hline \multirow{2}{*}{ Category } & \multirow{2}{*}{$\mathbf{W}$} & \multirow{2}{*}{$\mathbf{R}$} & \multicolumn{3}{|c|}{ Weighted ES } & \multicolumn{3}{|c|}{ Weighted ES \% } & \multicolumn{3}{|l|}{ Gap } & \multirow[b]{2}{*}{ Max-Gap } \\
\hline & & & H1 & H2 & H3 & H1 & H2 & H3 & H1 & H2 & H3 & \\
\hline G1 & 0.368938 & 1 & 2.896 & 3.295 & 3.359 & 57.921 & 65.896 & 67.171 & 42.079 & 34.104 & 32.829 & 42.079 \\
\hline G2 & 0.24501 & 2 & 3.426 & 3.678 & 3.816 & 68.511 & 73.567 & 76.322 & 31.489 & 26.433 & 23.678 & 31.489 \\
\hline G3 & 0.221878 & 3 & 2.756 & 3.060 & 3.102 & 55.122 & 61.195 & 62.050 & 44.878 & 38.805 & 37.950 & 44.878 \\
\hline G4 & 0.163248 & 4 & 3.444 & 3.591 & 3.628 & 68.883 & 71.826 & 72.560 & 31.117 & 28.174 & 27.440 & 31.117 \\
\hline
\end{tabular}

TABLE XII. THE OVERALL WEIGHTED EVALUATION SCORES OF HOSPITALS ON IMPORTANCE GROUPS: FDM- FAHP MODEL

\begin{tabular}{|c|c|c|c|c|c|c|c|c|c|c|c|c|}
\hline \multirow{2}{*}{ Category } & \multirow{2}{*}{ W } & \multirow{2}{*}{$\mathbf{R}$} & \multicolumn{3}{|c|}{ Weighted ES } & \multicolumn{3}{|c|}{ Weighted ES \% } & \multicolumn{3}{|l|}{ Gap } & \multirow[b]{2}{*}{ Max-Gap } \\
\hline & & & H1 & $\mathbf{H} 2$ & $\mathbf{H 3}$ & H1 & $\mathbf{H} 2$ & H3 & H1 & H2 & $\mathbf{H 3}$ & \\
\hline G1 & 0.419178 & 1 & 0.384 & 0.452 & 0.463 & 48.025 & 56.443 & 57.915 & 51.975 & 43.557 & 42.085 & 51.975 \\
\hline G2 & 0.241367 & 2 & 0.483 & 0.534 & 0.562 & 60.429 & 66.795 & 70.279 & 39.571 & 33.205 & 29.721 & 39.571 \\
\hline G3 & 0.178825 & 3 & 0.387 & 0.429 & 0.436 & 48.343 & 53.658 & 54.504 & 51.657 & 46.342 & 45.496 & 51.657 \\
\hline G4 & 0.160506 & 4 & 0.475 & 0.529 & 0.537 & 59.368 & 66.164 & 67.135 & 40.632 & 33.836 & 32.865 & 40.632 \\
\hline
\end{tabular}

4) Fourth Stage: Structured comparison of the OHLR levels of the hospitals using AHP.

In this stage, a structured comparison of the OHLR levels of hospitals, according to their overall weighted scores (C4), their overall weighted scores on each original category of indicators (C4-1, C4-2, C4-3, and C4-4), and their evaluation scores on each importance class (G1, G2, G3, and G4).

As all ambiguous and vague problems associated with the early implemented evaluation steps were solved using FAHP and FDM methods, there is no longer needed to use the fuzzy based technique to structurally compare the organizational health literacy responsiveness levels of hospitals. So, The AHP method will be used; the same analytic hierarchy process procedures should be applied to compare them. This stage is used for pairwise evaluation of the indicators' level of hospitals, so the alternatives of the MCDM problem are the indicators' and categories' health literacy responsiveness levels of three hospitals ( $\mathrm{H} 1, \mathrm{H} 2$, and $\mathrm{H} 3$ ). The gap between the comparative organizational health literacy responsiveness levels of two hospitals' indicators will decide which hospital is doing worst, or need more financial support at a whole system, specific group of indicators.

In this study, the total comparison processes are nine; one process at the overall OHLR level, four processes at the original domain level, and four processes at the importance domain level, for each process need to map the gap scale $(0-$ max gap value) to the 9-stage analytic hierarchy process score.
The result is a table where each GAP interval represents an analytic hierarchy process score, which is verbally described the situation.

The proposed model used a dynamical table [Table XIII] for mapping the related implementation gaps of hospital to 9 point scale, with interval equals (max gap/9).

For example, if the evaluation scores of the three hospitals on the indicator ' $\mathrm{C} 4$ ' are $(0.423,0.480$ and 0.494$)$, the related implementation gaps of them are (47.110, 40.003, and $38.238)$, and the max gap is 47.110 . This means the (0-47.110) gape scale should be mapped to 9 point scale, with interval equals 5.23; the first analytic hierarchy process score level (1) will be mapped to the (0-5.23), while the second level well be mapped to the $(5.24-10.46), \ldots$, the last level (9) will be mapped to the (41.89-47.11). This also means that the first hospital is the worst one, and the implementation gap between it and the second hospital is 7.1. Then, the analytic hierarchy process score is - as it corresponds to the GAP interval 2-2 if the first hospital is compared with the second or third, and it is $1 / 2$ if the second or third hospital is compared with the first. By the same way, the analytic hierarchy process score is 1, if the second and third hospitals compared with each other. This process was repeated 9 times and the results are presented in the following analysis section. This multi measurement scale was implemented instead of the suggested by [22] static mapping scheme; the static measurement scale is presented in Table XIV.

TABLE XIII. MAPPING BETWEEN THE ANALYTIC HIERARCHY PROCESS SCORE AND EVALUATION GAPS

\begin{tabular}{|c|c|c|c|c|c|c|c|c|c|c|}
\hline AHP process Score & & 1 & 2 & 3 & 4 & 5 & 6 & 7 & 8 & 9 \\
\hline \multirow{8}{*}{$\begin{array}{l}\text { Dynamic } \\
\text { Gap scale }\end{array}$} & $\mathrm{C} 4$ & 5.23 & 10.47 & 15.70 & 20.94 & 26.17 & 31.41 & 36.64 & 41.88 & 47.11 \\
\hline & $\mathrm{C} 4-1$ & 8.41 & 16.82 & 25.23 & 33.64 & 42.05 & 50.46 & 58.87 & 67.28 & 75.69 \\
\hline & $\mathrm{C} 4-2$ & 3.36 & 6.71 & 10.07 & 13.43 & 16.78 & 20.14 & 23.50 & 26.85 & 30.21 \\
\hline & $\mathrm{C} 4-3$ & 2.46 & 4.93 & 7.39 & 9.85 & 12.31 & 14.78 & 17.24 & 19.70 & 22.17 \\
\hline & $\mathrm{C} 4-4$ & 5.21 & 10.42 & 15.63 & 20.83 & 26.04 & 31.25 & 36.46 & 41.67 & 46.88 \\
\hline & G1 & 5.78 & 11.55 & 17.33 & 23.10 & 28.88 & 34.65 & 40.43 & 46.20 & 51.98 \\
\hline & G2 & 4.40 & 8.79 & 13.19 & 17.59 & 21.98 & 26.38 & 30.78 & 35.17 & 39.57 \\
\hline & G3 & 5.74 & 11.48 & 17.22 & 22.96 & 28.70 & 34.44 & 40.18 & 45.92 & 51.66 \\
\hline
\end{tabular}


TABle XiV. Mapping Between the Analytic Hierarchy Process SCore and Five Point Evaluation GaPS [16]

\begin{tabular}{|l|l|l|}
\hline AHP process Score & 5-point scale & Persentage scale \\
\hline 9 & $4.44-5$ & $88.89-100$ \\
\hline 8 & $3.89-4.44$ & $77.78-88.89$ \\
\hline 7 & $3.33-3.89$ & $66.67-77.78$ \\
\hline 6 & $2.78-3.33$ & $55.56-66.67$ \\
\hline 5 & $2.22-2.78$ & $44.44-55.56$ \\
\hline 4 & $1.67-2.22$ & $33.33-44.44$ \\
\hline 3 & $1.11-1.67$ & $22.22-33.33$ \\
\hline 2 & $0.56-1.11$ & $11.11-22.22$ \\
\hline 1 & $0-0.56$ & $0-11.11$ \\
\hline
\end{tabular}

\section{STRUCTURED COMPARISON RESULTS AND ITS DISCUSSION}

As it explained previously, the proposed model (A) depends on three different procedures that distinguish it from the model (B) that was proposed in study [22]; It relies on the fuzzy hierarchical analysis technique instead of the classical hierarchical analysis technique for the purpose of determining the weights of indicators and criteria; It depends on the fuzzy Delphi technique instead of the qualitative evaluation technique that depends on a five-point Likert scale for assessing literacy practices of hospitals. It also uses a multimeasurement scale, instead of the single one to link the evaluation results with the structured comparison scale, in order to obtain more accurate comparative results. on the overall weighted scores of implementation (C4 - level), the overall weighted scores on each sub category of indicators (SC-level: C4-1, C4-2, C4-3, and C4-4), and on each importance class (G-level: G1, G2, G3, and G4).

Table XV and Fig. 3 show, the structured comparison results of three models: (A, B, and C); the third model (C) is built based on the qualitative-AHP evaluation methods, which are used by the (B) model and it used a multi-measurement scale of the first model (A) for structured comparison purpose. found:

By analyzing the results of the study, the following were

It has become clear that the model (B) gives consistent comparative results for all nine comparison cases, and this means that the ratios that have been assigned to alternatives according to this model are not accurate as required. This result can be explained by the nature of the evaluation findings themselves; the convergence of evaluation results has been clearly observed, with very little variation in the application gap for alternatives; It is in a range of (0-0.56). This makes the results of the process of mapping these results to the levels used to study the comparison are limited to a single level, and corresponded to the first AHP - comparison assessment level (referred to Table XVI), and This in turn generates equal comparison rates for alternatives, 33 percent each (Fig. 3).

Although this model does not address the ambiguity associated with the evaluation process, it is appropriate for the purpose of study, if one condition is met. Only if the results of the application gap for alternatives are significantly different, and can be mapped to more than one comparison level. Unfortunately, in practice that cannot be guaranteed. This makes us stress the need to use multi-measurement scale to link the application gap of alternatives to the AHP comparison scale (Model C). Therefore, in the following sub section, the results of the proposed model (A) will be compared with those which were acquired by the model(C).

TABLE XV. The Structured Comparasion Results OF ALl Models

\begin{tabular}{|c|c|c|c|c|c|c|c|c|c|c|}
\hline \multirow[t]{2}{*}{$\mathbf{L}$} & \multirow{2}{*}{ Category } & \multicolumn{3}{|c|}{ The proposed model (A) } & \multicolumn{3}{|c|}{ The qualitative - AHP [22](B) } & \multicolumn{3}{|c|}{$\begin{array}{l}\text { The qualitative - AHP } \\
\text { (Dynamic mapping) (C) }\end{array}$} \\
\hline & & H1 & H2 & H3 & H1 & H2 & H3 & H1 & H2 & H3 \\
\hline $\mathrm{C} 4$ & $\mathrm{C} 4$ & $50.00 \%$ & $25.00 \%$ & $25.00 \%$ & $33.33 \%$ & $33.33 \%$ & $33.33 \%$ & $50.00 \%$ & $25.00 \%$ & $25.00 \%$ \\
\hline \multirow{4}{*}{$\mathrm{SC}$} & $\mathrm{C} 4-1$ & $41.26 \%$ & $32.75 \%$ & $25.99 \%$ & $33.33 \%$ & $33.33 \%$ & $33.33 \%$ & $54.99 \%$ & $24.02 \%$ & $20.98 \%$ \\
\hline & $\mathrm{C} 4-2$ & $54.99 \%$ & $24.02 \%$ & $20.98 \%$ & $33.33 \%$ & $33.33 \%$ & $33.33 \%$ & $54.99 \%$ & $24.02 \%$ & $20.98 \%$ \\
\hline & $\mathrm{C} 4-3$ & $50.00 \%$ & $25.00 \%$ & $25.00 \%$ & $33.33 \%$ & $33.33 \%$ & $33.33 \%$ & $50.00 \%$ & $25.00 \%$ & $25.00 \%$ \\
\hline & $\mathrm{C} 4-4$ & $54.99 \%$ & $24.02 \%$ & $20.98 \%$ & $33.33 \%$ & $33.33 \%$ & $33.33 \%$ & $50.00 \%$ & $25.00 \%$ & $25.00 \%$ \\
\hline \multirow[t]{4}{*}{ G } & G1 & $50.00 \%$ & $25.00 \%$ & $25.00 \%$ & $33.33 \%$ & $33.33 \%$ & $33.33 \%$ & $50.00 \%$ & $25.00 \%$ & $25.00 \%$ \\
\hline & G2 & $54.99 \%$ & $24.02 \%$ & $20.98 \%$ & $33.33 \%$ & $33.33 \%$ & $33.33 \%$ & $54.99 \%$ & $24.02 \%$ & $20.98 \%$ \\
\hline & G3 & $41.26 \%$ & $32.75 \%$ & $25.99 \%$ & $33.33 \%$ & $33.33 \%$ & $33.33 \%$ & $50.00 \%$ & $25.00 \%$ & $25.00 \%$ \\
\hline & $\mathrm{C} 4$ & $50.00 \%$ & $25.00 \%$ & $25.00 \%$ & $33.33 \%$ & $33.33 \%$ & $33.33 \%$ & $41.26 \%$ & $32.75 \%$ & $25.99 \%$ \\
\hline
\end{tabular}




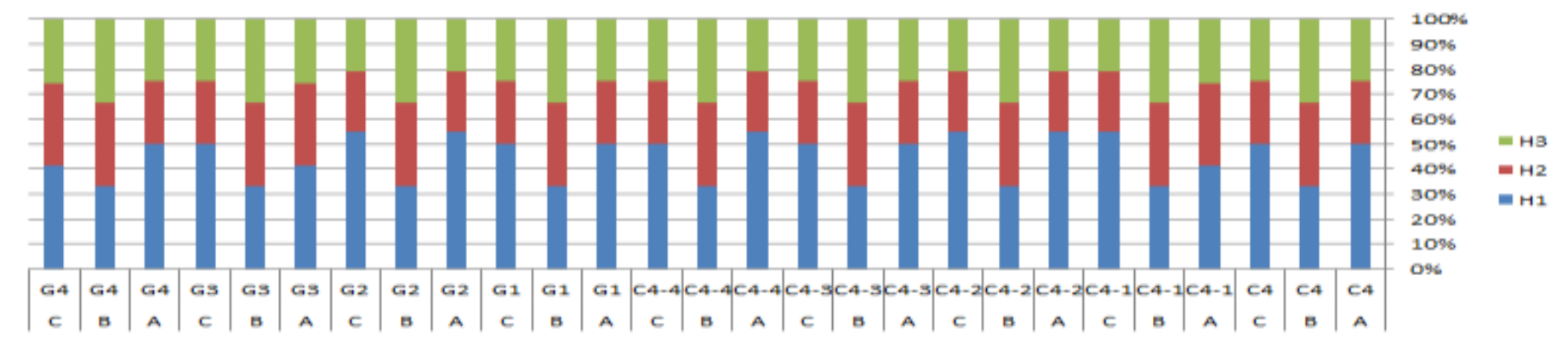

Fig. 3. The Structured Comparison Results of All Models.

TABLE XVI. The Single AND Multi-MEASURment SCALE

\begin{tabular}{|c|c|c|c|c|c|c|c|c|c|c|c|c|c|}
\hline \multirow[t]{2}{*}{$\mathbf{L}$} & \multirow[t]{2}{*}{ Category } & \multicolumn{3}{|l|}{ ES } & \multicolumn{3}{|l|}{ Gaps } & \multicolumn{3}{|c|}{$\begin{array}{l}\text { The AHP mapped level of the } \\
\text { gap level using single measurement } \\
\text { scale }(0-5)\end{array}$} & \multicolumn{3}{|c|}{$\begin{array}{l}\text { The AHP mapped level of the gap } \\
\text { level using multi - measurement scale }\end{array}$} \\
\hline & & H1 & H2 & H3 & H1 & H2 & H3 & H1vs H2 & H1vs H2 & H2vs H3 & H1vs H2 & H1vs H2 & H2vs H3 \\
\hline \multirow{4}{*}{ SC } & C4-1 & 3.148 & 3.499 & 3.565 & 0.3516 & 0.4179 & 0.0663 & 1 & 1 & 1 & 2 & 3 & 1 \\
\hline & $\mathrm{C} 4-2$ & 3.186 & 3.492 & 3.655 & 0.3054 & 0.4686 & 0.1632 & 1 & 1 & 1 & 2 & 3 & 1 \\
\hline & $\mathrm{C} 4-3$ & 3.030 & 3.257 & 3.281 & 0.2278 & 0.2512 & 0.0234 & 1 & 1 & 1 & 2 & 2 & 1 \\
\hline & C4-4 & 3.134 & 3.357 & 3.399 & 0.2237 & 0.265 & 0.0413 & 1 & 1 & 1 & 2 & 2 & 1 \\
\hline
\end{tabular}

The results of the comparison of the output of the two models (A and C) at the general level of health literacy showed that the first hospital was most in need for the financial support allocated for improving the level of health literacy. This result suggests that the first hospital have to get 50 per cent of the resources, whereas other hospitals have to get 25 per cent each.

Also, results of the comparison of their output at the subdomain level of the fourth standard used in this study (SClevel) and at the sub-class level of indicators classified according to their importance (G-level) show that there are differences in the financial support rates that those hospitals have to get.

To compare results of these models, the average change in the output of two models, which are the values of the rates each hospital must have and the Bland-Atman agreement analysis between them were used.

The Bland-Atman agreement analysis is implemented using the following steps [50]: (1) calculate the average weights and differences in them, (2) determine the mean of differences (d), and (3) compute limits of agreement. With assumption that the differences are normally distributed, and prediction interval of $95 \%$ as suggested by $[50,51]$; the limits of agreement were calculated as $(\mathrm{d}+1.69 * \mathrm{Sd} ; \mathrm{d}-1.69 *$ $\mathrm{Sd})$, where $\mathrm{Sd}$ is the standard deviation of the differences.

The results of the analysis showed that the average change in the financial support ratios that the first hospital has to get was roughly $2.02 \%$; and it were $2.08 \%$, and $1.22 \%$ in the case of the second and third hospitals. This is because there is no change in the rates assigned by these models for $0.55 \%$, $0.55 \%$, and $0.45 \%$ of the comparative processes, respectively.

It also presents that the proposed model (A) gives more accurate evaluation results in comparison with the other model; multiple levels of importance were assigned to indicators, and sub-domains that got one level in the other model. For example, Using the fuzzy based results (model A), For the first hospital case, two deferent values of importance $41.26 \%, 54.9 \%$ were assigned to the (C4-1, and $\mathrm{C} 4-2)$ classes, while the same rate $54 \%$ has been assigned to them when the Qualitative - AHP results were used. For the same reason the proposed model gave better results when comparing the results of hospitals on the (C4-3, and C4-4), and (G1, and G3) pairs. The similar findings have been obtained in the case of other hospitals.

In addition, in the case of hospital (1), the values of ($0.0048)$ and (0.033) were obtained, the first represents the mean of difference; the second describes the standard deviation of the differences for the investigated models. In addition, the value of (0.010) upper limit and (- 0.00079) lower limit of the confidence interval (0.0113) for the investigated pair were shown. This means that a $95 \%$ of the differences in weights between models are possible to fall in the scope $(0.010,-0.00079)$. By the same way, a $95 \%$ of the differences in weights of $(\mathrm{H} 2)$ between the two investigated models are possible to fall in the scope $(0.0084,-0.0002)$, within an (0.0082) interval, and the same percentage of the differences of the third hospitals' weights between the two models are possible to fall in the scope $(0.0025,-0.0014)$, within an (0.0093).interval.

Finally, the analysis of the average change in the hospitals' rates of both models shows that the fuzzy based model (A) is better than its equivalent classical model (B) in that it gives non-convergent evaluation results, allowing for better arrangement of criteria, because of that the fuzzy algorithm modifies experts' opinions by using three-valued numbers as an alternative to the one valued numbers representing the AHP rating levels, and this considerably affects the final weight [52]. Also, the agreement results indicate that the limits of agreement between these models are small enough to be confident that the proposed model (A) can be used in place of 
the second one (C). Regarding this, the F_AHP-FDM based model for structured comparison of the OHLR level of hospitals will be recommended to use instead of the previously suggested Qualitative - AHP based model [22].

\section{CONCLUSION}

The results of the first and second stages show that, with the pairwise comparison using FAHP, it is possible to obtain a priority for each individual indicator and classify them into different groups, and, thus, it is very granular in the overall context of the OHL - standartd4. The fuzzy approach with the pairwise comparison by fuzzy AHP meets all of the requirements of the methodology. The results of the third stage show that the OHLR evaluation process is an important step to determine the development and enhancement directions. Additionally, these results show that with the evaluation using the fuzzy Delphi method, it is possible to obtain an OHLR level for each individual indicator in each organization, and, thus, it is very granular in the overall context of the OHL - standartd4 for the hospital sector. The fuzzy Delphi method also meets all of the requirements of the methodology. Similarly, it is shown that the weighting of the pairwise comparisons of the OHLR level for the hospitals can be mapped granularly to the indicators of the OHL - fourth standard. Additionally, it was possible to derive the FAHP score from the OHLR levels automatically. This makes it easy to compare the rankings of the hospitals. The only effort that needs to be invested is the prioritization of the HL indicators. The results show that all hospitals need additional resources and actions to improve their status. Additionally, it shows which hospital must get the biggest share of the support budget (the first hospital in our example). The results suggest that the approach works in conjunction with the simulation data. However, it can be strongly assumed that the method is directly applicable to public hospitals with the same or similar results.

Also, the comparison results of the application of the proposed model with those obtained using the qualitative AHP based model suggest that the FDM-FAHP based model is well suited to define the organizational health literacy responsiveness level of different hospitals. The results of the pairwise comparison suggest that analytic hierarchy process based on the based on the multi-measurement scale is suited to compare the organizational health literacy responsiveness levels and to find the hospital with the worst health literacy responsiveness level within a public hospital sector. It has been proven that a comparison within some of the healthcare hospitals is possible using this integrated model. This proposed model has demonstrated how fuzzy analytic hierarchy process and fuzzy Delphi methods might be used together to assist decision makers with the evaluation and prioritization of organizational health literacy responsiveness factors in one sector, evaluation of the organizational health literacy responsiveness levels in each hospital in this sector, and rank of these hospitals by their actual organizational health literacy responsiveness level for future healthcare development, social responsibility, and sustainable planning objectives.

\section{ACKNOWLEDGMENTS}

This research was supported by the Deanship of Scientific Research at Prince Sattam bin Abdulaziz University.

\section{REFERENCES}

[1] V.A. Luyckx., M Tonelli and J W. Stanifer, "The global burden of kidney disease and the sustainable development goals ," Bulletin of the World Health Organization 96(6), 2018, pp 414-422. https://doi.org/10.2471/blt.17.206441.

[2] E. A. Adeyemi, Y. A. Adebisi, and A. O. Babatunde,"Psychosocial Impacts of Chronic Kidney Disease and Dialysis Therapy," SciMedicine Journal, 3(2), 2021, pp 129-137. https://doi.org/10.28991/scimedj-20210302-5.

[3] F. Korançe,"The growing Relation between Environment and Public Health ," SciMedicine Journal, 3(2), 2021,pp 100-115. https://doi.org/10.28991/scimedj-2021-0302-3.

[4] X, Cao, "Corporate Social Responsibility," In Fair Development in China . Springer, Cham., 2017, pp. 119-134. https://doi.org/10.1007/978-3-319-43663-0_8.

[5] Mohammed M Said, Adel A Nasser and Abdualmajed A Alkhulaidi. , “ Prioritization of the Eco-hotels Performance Criteria in Yemen using Fuzzy Delphi Method,". International Journal of Applied Information Systems 12(36):20-29, March 2021, https://doi.org.10.5120/ijais2020451900.

[6] T. Floričić, "Sustainable Solutions in the Hospitality Industry and Competitiveness Context of 'Green Hotels," Civil Engineering Journal, vol. 6, no. 6, pp. 1104-1113, Jun. 2020. https://doi.org/10.28991/cej2020-03091532.

[7] D. N. Jackson, N. Trivedi, and C. Baur, " Re-prioritizing Digital Health and Health Literacy in Healthy People 2030 to Affect Health Equity ," Health Communication, 2020, pp. https://doi.org/10.1080/10410236.2020.1748828.

[8] A. A. Nasser, A. A. Alkhulaidi, M. N. Ali, M. Hankal, and Al-olofe M., "A Study on the impact of multiple methods of the data normalization on the result of SAW, WED and TOPSIS ordering in Healthcare Multiattributtes Decision Making Systems based on EW, ENTROPY, CRITIC and SVP weighting approaches," Indian Journal of Science and Technology, vol. 12, no. 4, pp. 1-21, Jan. 2019.. https://doi.org/10.17485/ijst/2019/v12i4/140756.

[9] A. A. Nasser, A. A. Alkhulaidi, M. N. Ali, M. Hankal, and Al-olofe M., "A Weighted Euclidean Distance - Statistical Variance Procedure based Approach for Improving The Healthcare Decision Making System In Yemen," Indian Journal of Science and Technology, vol. 12, no. 3, pp. 1-15, Jan. 2019. https://doi.org/10.17485/ijst/2019/v12i3/140661.

[10] International Working Group Health Promoting Hospitals and Health Literate Healthcare Organizations (Working Group HPH and HLO): International Self-Assessment Tool Organizational Health Literacy (Responsiveness) for Hospitals - SAT-OHL-Hos-v1.0ENinternational.Vienna:WHO Collaborating Centre for Health Promotion in Hospitals and Healthcare (CC-HPH), 2019. Availible at : https://www.hphnet.org/wp-content/uploads/2020/04/SAT-OHL-Hosv1-0-EN-international_final.pdf, acceced March 2021.

[11] Y. Yu, A. He, S. Zheng, J. Jiang, J. Liang, B. Shrestha, and P. Wang, "How does health literacy affect the utilization of basic public health services in Chinese migrants?," Health Promotion International, Apr. 2021. https://doi.org/10.1093/heapro/daab040.

[12] D. J. Chisolm, H. E. Keedy, L. C. Hart, L. J. Chavez, M. Dolce, J. Morack, C. Grannis, and K. Kelleher, "Exploring Health Literacy, Transition Readiness, and Healthcare Utilization in Medicaid Chronically Ill Youth," Journal of Adolescent Health, May 2021. https://doi.org/10.1016/j.jadohealth.2021.03.023.

[13] E. Calero-Molina, E. Hidalgo, L. Rosenfeld, J. M. Verdú-Rotellar, J. Verdú-Soriano, A. Garay, L. Alcoberro, S. Jimenez-Marrero, P. Garcimartin, S. Yun, C. Guerrero, P. Moliner, C. Delso, L. Alcober, C. Enjuanes, and J. Comin-Colet, "The relationship between self-care, long-term mortality, and heart failure hospitalization: insights from a real-world cohort study," European Journal of Cardiovascular Nursing, May 2021. https://doi.org/10.1093/eurjcn/zvab011. 
[14] O. Lindly, M. Crossman, M. Eaves, L. Philpotts, and K. Kuhlthau, "Health Literacy and Health Outcomes Among Children With Developmental Disabilities: A Systematic Review," American Journal on Intellectual and Developmental Disabilities, vol. 125, no. 5, pp. 389407, Sep. 2020. https://doi.org/10.1352/1944-7558-125.5.389.

[15] M. Fabbri, M. H. Murad, A. M. Wennberg, P. Turcano, P. J. Erwin, F. Alahdab, A. Berti, S. M. Manemann, K. J. Yost, L. J. Finney Rutten, and V. L. Roger, "Health Literacy and Outcomes Among Patients With Heart Failure," JACC: Heart Failure, vol. 8, no. 6, pp. 451-460, Jun. 2020. https://doi.org/10.1016/j.jchf.2019.11.007.

[16] D. Schillinger, R. Balyan, S. A. Crossley, D. S. McNamara, J. Y. Liu, and A. J. Karter, "Employing computational linguistics techniques to identify limited patient health literacy: Findings from the ECLIPPSE study," Health Services Research, vol. 56, no. 1, pp. 132-144, Sep. 2020. https://doi.org/10.1111/1475-6773.13560.

[17] Adel A. Nasser, Nada Kh. A. Al Ansi, Naif A. N. Al Sharabi, "On The Standardization Practices of the Information Security Operations in Banking Sector: Evidence from Yemen," International Journal of Scientific Research in Computer Science and Engineering, Vol.8, Issue.6, pp.8-18, 2020. https://www.isroset.org/pdf paper_view.php? paper_id=2166\&2-ISROSET-IJSRCSE-05015.pdf.

[18] A. N. Al-Shameri, "Hierarchical Multilevel Information security gap analysis models based on ISO 27001: 2013," International Journal of Scientific Research in Multidisciplinary Studies, 3(11),2017, 14-23. https://www.isroset.org/pub_paper/IJSRMS/3-IJSRMS-0588-24.pdf.

[19] A. Nasser, "Information security gap analysis based on ISO 27001: 2013 standard: A case study of the Yemeni Academy for Graduate Studies, Sana'a, Yeme,n"”. Int. J. Sci. Res. in Multidisciplinary Studies Vol, 3(11).2017. https://www.isroset.org/pub_paper/IJSRMS/2-IJSRMS0573.pdf.

[20] H. Storms, N. Claes, B. Aertgeerts, and S. Van den Broucke, "Measuring health literacy among low literate people: an exploratory feasibility study with the HLS-EU questionnaire," BMC Public Health, vol. 17, no. 1, May 2017. https://doi.org/10.1186/s12889-017-4391-8.

[21] K. Sørensen, J. M. Pelikan, F. Röthlin, K. Ganahl, Z. Slonska, G. Doyle, J. Fullam, B. Kondilis, D. Agrafiotis, E. Uiters, M. Falcon, M. Mensing, K. Tchamov, S. van den Broucke, and H. Brand, "Health literacy in Europe: comparative results of the European health literacy survey (HLS-EU)," The European Journal of Public Health, vol. 25, no. 6, pp. 1053-1058, Apr. 2015. https://doi.org/10.1093/eurpub/ckv043.

[22] A. Schmid and S. Pape, "A Structured Comparison of the Corporate Information Security Maturity Level," IFIP Advances in Information and Communication Technology, pp. 223-237, 2019. https://doi.org/10.1007/978-3-030-22312-0_16.

[23] S. Greco, J. Figueira and M. Ehrgott , Multiple criteria decision analysis , New York: Springer., 2016. https://doi.org/10.1007/978-1-4939-30944.

[24] A. A. Afsordegan, "Contribution to multi-criteria decision making in sustainable energy management based on fuzzy and qualitative reasoning," Tesi doctoral, UPC, Departament de Projectes d'Enginyeria, 2015. Disponible a: http://hdl.handle.net/2117/96001.

[25] Adel A Nasser, Abdualmajed Al-Khulaidi and Mijahed N. Aljober, “ Measuring the Information Security Maturity of Enterprises under Uncertainty Using Fuzzy AHP," International Journal of Information Technology and Computer Science(IJITCS), 2018; 10, 10-25.DOI: https://doi.org/10.5815/ijitcs.2018.04.02.

[26] R. J. Andrews, J. V. Rosenfeld, and N. Crisp, "The Importance of Surgical Care to Achieve the United Nations Sustainable Development Goal for Healthy Lives by 2030," JAMA Health Forum, vol. 2, no. 6, p. e211213, Jun. 2021.https://doi.org/10.1001/jamahealthforum.2021.1213.

[27] M. C. Watson and J. Lloyd, "Creating health promoting schools will improve population health and help reduce inequalities," BMJ, p. n1290, May 2021.https://doi.org/10.1136/bmj.n1290.

[28] S.S. Budhathoki, P.K. Pokharel,S. Good, S. Limbu, M. Bhattachan, and R.H.Osborne, "The potential of health literacy to address the health related UN sustainable development goal 3 (SDG3) in Nepal: a rapid review ,"BMC health services research, 17(1), 2017, pp 1-13. https://doi.org/10.1186/s12913-017-2183-6.
[29] L. Mutea, S. Ontiri, F. Kadiri, K. Michielesen, and P. Gichangi, “Access to information and use of adolescent sexual reproductive health services: Qualitative exploration of barriers and facilitators in Kisumu and Kakamega, Kenya," PLOS ONE, vol. 15, no. 11, p. e0241985, Nov. 2020. https://doi.org/10.1371/journal.pone.0241985.

[30] Fasoulis and Rafet, "Embracing Sustainability in Shipping: Assessing Industry's Adaptations Incited by the, Newly, Introduced 'triple bottom line' Approach to Sustainable Maritime Development," Social Sciences, vol. 8, no. 7, p. 208, Jul. 2019. https://doi.org/10.3390/socsci8070208.

[31] L. Mishra, "Corporate social responsibility and sustainable development goals: A study of Indian companies," Journal of Public Affairs, vol. 21, no. 1, Apr. 2020. https://doi.org/10.1002/pa.2147.

[32] D. Pesmatzoglou, I.E. Nikolaou, K.I., Evangelinos, and S. Allan, "Extractive multinationals and corporate social responsibility: a commitment towards achieving the goals of sustainable development or only a management strategy? " Journal of International Development, 26(2), 2014, pp.187-206. https://doi.org/10.1002/jid.2871.

[33] K. Sørensen, and H. Brand , "Health literacy-A strategic asset for corporate social responsibility in Europe ," Journal of health communication, $16(3), 2011, \quad$ pp.322327.https://doi.org/10.1080/10810730.2011.606072.

[34] T. L. Saaty, "Optimization by the Analytic Hierarchy Process," Jan. 1979. https://doi.org/10.21236/ada214804

[35] J. Franek and A. Kresta, "Judgment Scales and Consistency Measure in AHP," Procedia Economics and Finance, vol. 12, pp. 164-173, 2014. https://doi.org/10.1016/s2212-5671(14)00332-3.

[36] J. Y. Yap,C.C. Ho, and C.Y. Ting, "Aggregating Multiple Decision Makers' Judgement," In Intelligent and Interactive Computing . Springer, Singapore., 2019, pp. 13-21. https://doi.org/10.1007/978-98113-6031-2_26.

[37] Kaya, B. Çiçekalan, and F. Çebi,"Location selection for WEEE recycling plant by using Pythagorean fuzzy AHP," Journal of Intelligent and Fuzzy Systems, 38(1), 2020, pp. 1097-1106 https://doi.org/10.3233/jifs-179471.

[38] N. Dalkey, and O. Helmer, "An experimental application of the Delphi method to the use of experts," Management Science, 9(3), 1963, pp. 458-467. https://doi.org/10.1287/mnsc.9.3.458.

[39] S.K. Manakandan, I. Rosnah, R.J. Mohd, and R. Priya, "Pesticide applicators questionnaire content validation: A fuzzy Delphi method," $\begin{array}{llll}\text { Med J } & \text { Malaysia, } 228 .\end{array}$ https://pubmed.ncbi.nlm.nih.gov/28889134/.

[40] M. Stuit, "Implementing the Information Literacy Framework: A Practical Guide for Librarians," Public Services Quarterly, vol. 14, no. 4, pp. 348-349, Oct. 2018. https://doi.org/10.1080/15228959.2018.1537987.

[41] C. Pennell, "Implementing a New Literacy Program: Professional Learning and Coaching," Evaluating the K-12 Literacy Curriculum, pp. 133-136, Feb. 2020. https://doi.org/10.4324/9780429261107-12.

[42] A. G. Brega, M. A. G. Freedman, W. G. LeBlanc, J. Barnard, N. M. Mabachi, M. Cifuentes, K. Albright, B. D. Weiss, C. Brach, and D. R. West, "Using the Health Literacy Universal Precautions Toolkit to Improve the Quality of Patient Materials," Journal of Health Communication, vol. 20, no. sup2, pp. 69-76, Oct. 2015.https://doi.org/10.1080/10810730.2015.1081997.

[43] L.Y. Prince, , C. Schmidtke, J.K. Beck, and K.B. Hadden , "An assessment of organizational health literacy practices at an academic health center ," Quality management in health care, 27(2), 2018,pp.9397. https://doi.org/10.1097/qmh.0000000000000162.

[44] N. Kružliaková, K. Porter, P. A. Ray, V. Hedrick, D. J. Brock, and J. Zoellner, "Understanding and Advancing Organizational Health Literacy Within a Public Health Setting," HLRP: Health Literacy Research and Practice, vol. 5, no. 1, Jan. 2021.https://doi.org/10.3928/24748307-20210114-01.

[45] C. A. Vamos, E. L. Thompson, S. B. Griner, L. G. Liggett, and E. M. Daley, "Applying Organizational Health Literacy to Maternal and Child Health," Maternal and Child Health Journal, vol. 23, no. 5, pp. 597-602, Jan. 2019 https://doi.org/10.1007/s10995-018-2687-7.

[46] H. KUCUKALI, O. ATAC, O. OZER, and O. HAYRAN, "Evaluation of individual health literacy among inpatients of different types of 
hospitals in Istanbul," Marmara Medical Journal, May 2020. https://doi.org/10.5472/marumj.740539.

[47] H. Shekari , "Investigating and Prioritizing Factors Affecting Health Literacy in University Students of Yazd Using Artificial Neural Network Technique ," Journal of Community Health Research, 9(1),2019, pp 29-37. https://doi.org/10.18502/jchr.v8i1.559.

[48] D.Y. Chang, "Applications of the extent analysis method on fuzzy AHP," European journal of operational research, 95(3), 1996, pp. 649655. https://doi.org/10.1016/0377-2217(95)00300-2.

[49] H.A. Linstone, and M. Turoff, "The Delphi method ," Reading, MA: Addison-Wesley., 1975. https://doi.org/10.2307/1268751.
[50] J M Bland, and G A Douglas , "Statistical methods for assessing agreement between two methods of clinical measurement. ," The lancet,1989;1:307-310, https://doi.org/10.1016/S0140-6736(86)90837-8.

[51] J M Bland, and G A Douglas, "Measuring agreement in method comparison studies ," Statistical Methods in Medical Research, 1999;8.2. https://doi.org/10.1177\%2F096228029900800204.

[52] R. Mosadeghi, J. Warnken, R. Tomlinson, and H. Mirfenderesk, "Comparison of Fuzzy-AHP and AHP in a spatial multi-criteria decision making model for urban land-use planning," Computers, Environment and Urban Systems, vol. 49, pp. 54-65, Jan. 2015. https://doi.org/10.1016/j.compenvurbsys.2014.10.001. 